BBR 00439

\title{
Asymmetry in the effects of unilateral 6-OHDA lesions on eating and drinking evoked by hypothalamic stimulation
}

\author{
GUY MITTLEMAN, PAUL J. FRAY* and ELLIOT S. VALENSTEIN \\ Psychology Department and Neuroscience Laboratory Building, The University of Michigan, Ann Arbor, MI 48104-1687 (U.S.A.) \\ (Received November 9th, 1984) \\ (Revised version received January 30th, 1985) \\ (Accepted February 12th, 1985)
}

Key words: electrical stimulation of the lateral hypothalamus - eating - drinking - 6-hydroxydopamine - dopamine - lesion - asymmetry - rat

The present experiment investigated the effects of unilateral 6-hydroxydopamine lesions of the caudate nucleus and nucleus accumbens on eating and drinking evoked by electrical stimulation of the lateral hypothalamus (ESLH). Lesions were made on either the 'dominant' or 'non-dominant' hemisphere as defined by an amphetamine-rotation test. We report here that lesions of the 'dominant hemisphere' were significantly more effective in disrupting ESLH-evoked behavior as well as producing longerlasting deficits in somatosensory responsiveness as measured by the 'tactile extinction test'.

It is well established that electrical stimulation of the lateral hypothalamus (ESLH) can elicit eating and drinking in many animals ${ }^{34}$. Although it was initially suggested that ESLH activated the specific neural systems controlling homeostatic consummatory behavior such as eating and drinking in response to hunger and thirst ${ }^{5,6}$, this view has been seriously challenged, by demonstrations that: identical stimulation of a given electrode site typically evokes several different behaviors depending on availability of stimuli ${ }^{37,38}$, taste preferences of stimulated animals are different from those of hungry or thirsty animals ${ }^{30,33}$; individual differences in predisposition to eat or drink during ESLH cannot be explained either by electrode placement ${ }^{4,41}$ or differences in the amount of food or water normally ingested ${ }^{17}$.

The view that ESLH-elicited behavior is a response to a much less specific activating stimulus than hunger or thirst is supported by evidence of similarities between the behaviors evoked by tailpinch and schedule-induced polydipsia (SIP). These procedures all produce increased activation that can be channelled into a variety of ingestive and non-ingestive behaviors $1,7,16,28,35,36,39$. The demonstration that there is a strong correlation between the behavior displayed by individual animals during ESLH and SIP tests lends credibility to the suggestion that the behaviors elicited by these different conditions may have a common neural substrate ${ }^{18,21,35}$.

Behavior evoked by tail-pinch has been reported to be mediated by the nigrostriatal dopamine system ${ }^{2,3}$, and SIP has been shown to be attenuated or abolished by lesions of the mesolimbic dopamine pathway ${ }^{24,40}$. Preliminary evidence has indicated that the behavior evoked by ESLH can be disrupted by dopamine receptor blockers

\footnotetext{
* Current address: University of Cambridge, Dept. of Anatomy, Downing St, Cambridge CB2 3DY, U.K.

Correspondence: E.S. Valenstein, Neuroscience Laboratory Building, The University of Michigan, 1103 E. Huron St., Ann Arbor, MI 48104-1687, U.S.A.
} 
and intraventricular 6-hydroxydopamine (6OHDA) injections ${ }^{19,20,21,22,29}$.

The purpose of the present experiment was to investigate the role of dopamine in ESLH-elicited eating and drinking by unilateral destruction of dopamine terminals in the caudate nucleus and nucleus accumbens. Unilateral lesions were used because they avoided the debilitating motor impairments of bilateral lesions and because they made it possible to evaluate the importance of asymmetry in the nigrostriatal dopamine system ${ }^{11,14,15,26}$ for eating and drinking evoked by ESLH.

The subjects were 47 mature, male LongEvans hooded rats, bilaterally implanted with bipolar stainless steel electrodes in the lateral hypothalamus. In addition, 24 gauge guide cannulas were placed bilaterally just above the dorsal border of the caudate nucleus (CD) and nucleus accumbens (NAC). Following recovery from surgery, rats were tested for amphetamine-induced rotational behavior to estimate the degree of asymmetry in nigrostriatal DA. Each rat was placed in an automated spherical rotometer for a $15 \mathrm{~min}$ habituation period and then injected with $1.2 \mathrm{mg} / \mathrm{kg}$ (i.p.) D-amphetamine sulfate (AMPH) dissolved in saline. AMPH-induced rotational behavior was recorded for $60 \mathrm{~min}$. Based on the direction of the majority of full rotations (defined as 4 consecutive $90^{\circ}$ turns), the hemisphere contralateral to the preferred direction of rotation was defined as 'dominant' for rotational behavior, and the other hemisphere 'non-dominant'. It has previously been shown that the striatum contralateral to an animal's preferred direction of rotation has higher dopamine levels and greater metabolic activity as measured by the 2-deoxy-D-[ $\left.{ }^{14} \mathrm{C}\right]$ glucose autoradiographic method ${ }^{10,12}$.

One week to 10 days after the AMPH rotation test, animals were habituated to a Plexiglas chamber and tested for the behavior evoked by ESLH. Stimulation consisted of $20-\mathrm{s}$ trains of $60-\mathrm{Hz}$ sine waves alternating with $15-\mathrm{s}$ intertrial intervals. During testing, 75-mg food pellets (P.J. Noyes) were available on the floor, and a standard water bottle with a metal drinking tube was attached to one wall. Stimulation intensity was increased from $1 \mu \mathrm{A}$, by $1-\mu \mathrm{A}$ steps until animals ate or drank, or until they became either excessively agitated or displayed 'forced' motor responses, either of which precluded eating or drinking. Animals that ate or drank were given additional ESLH at a current intensity just above the 'threshold', until they ate or drank on 5 consecutive stimulations. After screening with the right hypothalamic electrode, animals were tested for their response to stimulation of the left electrode. All rats were retested on 3 separate occasions, separated by $48 \mathrm{~h}$, using the same procedure. The average current threshold for evoking ingestive behavior was $9.1 \mu \mathrm{A}$. The 16 rats that failed to eat and drink in response to stimulation at either electrode were eliminated from the experiment.

One week after completion of ESLH testing, 22 of the 31 rats that displayed consistent and reliable eating or drinking during ESLH were tested for asymmetry in sensorimotor responsiveness using the 'tactile extinction test' described by Shallert et al. ${ }^{31}$. This test is analogous to the 'simultaneous stimulation test' used clinically with patients recovering from brain damage ${ }^{1,3,32}$. A small piece of sticky tape (Pres-a-Ply Label, Dennison) was simultaneously placed on the radial aspect of each of the animal's forepaws and the latency to remove each label was recorded. The 'tactile extinction test' was repeated on 4 trials separated by 5 -min intertrial intervals and the time to remove the tape was averaged for each paw separately.

Following completion of the "tactile extinction test', all 31 animals were then lesioned unilaterally in either the 'dominant' $(n=16)$ or 'non-dominant' $(\mathbf{n}=15)$ hemisphere as determined by the AMPH-rotation test. Using the previously implanted cannulae, destruction of DA terminals in $\mathrm{CD}$ and NAC was accomplished by injection of 6-OHDA dissolved in $0.9 \%$ saline with $0.1 \%$ ascorbic acid. Details of this procedure are provided in the legend to Table I. All rats were retested for ESLH-evoked behavior at 7-day intervals for one month. The tactile extinction test was readministered at 7 and 21 days following the lesion. All animals were retested for AMPHinduced rotation 1-2 weeks after the second 'tactile extinction test'.

Animals $(n=27)$ were decapitated 5-6 weeks 


\section{TABLE I}

Mean dopamine levels (ng/mg wet tissue weight) and standard errors in lesioned and non-lesioned structures*

Note: $8 \mu \mathrm{g}$ of 6-OHDA were infused unilaterally in $4 \mu \mathrm{l}$ of vehicle at a rate of $1 \mu \mathrm{l} / \mathrm{min}$ through the cannula. Rats were pretreated with desmethylimipramine (DMI) $(25 \mathrm{mg} / \mathrm{kg})$, $30 \mathrm{~min}$ prior to infusion of 6-OHDA. Catecholamine content was determined using a method modified from Felice et al. (1978). DA and NE depletion were determined by the formula 100-(lesion side/non-lesion side $\times 100$ ). The 4 rats that had bilateral DA depletion and the 3 rats that had normal DA levels, presumably because of blocked cannulae, were eliminated from the data analysis.

\begin{tabular}{lcc}
\hline Structure & Lesioned & Non-lesioned \\
\hline Corpus striatum & $1.62 \pm 0.29$ & $9.59 \pm 0.73$ \\
Nucleus accumbens & $2.58 \pm 0.54$ & $4.94 \pm 0.55$ \\
Olfactory tubercle & $1.64 \pm 0.27$ & $3.84 \pm 0.34$
\end{tabular}

* There were no differences between dopamine levels of dominant and non-dominant sides.

after the 6-OHDA lesions. A biochemical analysis of DA and NE content in the CD, NAC and olfactory tubercle was made using high performance liquid chromatography with electrochemical detection. Cresyl violet-stained histological sections $(30 \mu \mathrm{m})$ of the more posterior portion of the brains was used to determine electrode placement.

When rested for ESLH-evoked behavior, the majority $(75 \%)$ of the animals with 'dominant' side lesions no longer ate or drank in response to stimulation. The animals were tested with current
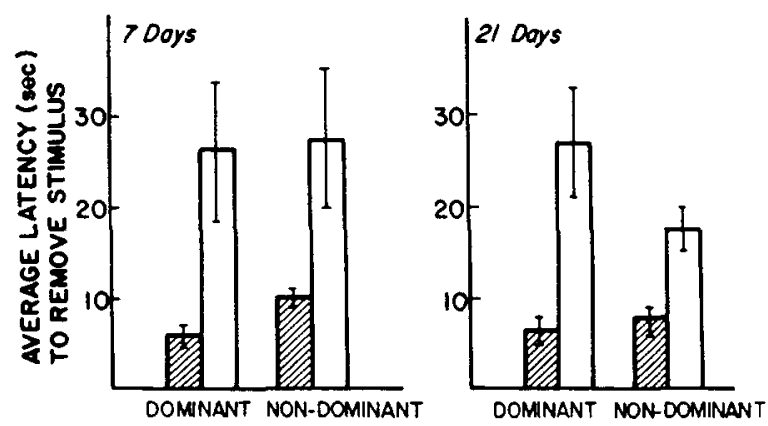

Fig. 1. The average ( \pm S.E.M. $)$ latency to remove the adhesive label from the radial aspect of the forelimb contralateral (open bar) and ipsilateral (striped bar) to a 'dominant' or 'non-dominant' lesion. Tests were performed at 7 (left) and 21 (right) days following the lesion. intensities up to $30 \mu \mathrm{A}$ unless the stimulation completely disrupted behavior at a lower intensity. In contrast, only $25 \%$ of the animals with 'non-dominant' side lesions no longer exhibited the ESLH-elicited ingestive behaviors. This difference is statistically significant (chi square $=6.0, \mathrm{df}=1, P<0.05)$. The elimination of ESLH-evoked behavior appeared to be longlasting. Of the 12 animals that failed to show ESLH-evoked eating and drinking at any current intensity, only 3 rats recovered this behavior within 1 month. All animals, however, displayed quite normal increases in locomotor activity when stimulated. The current threshold of the animals that continued to eat or drink in response to ESLH after the lesions was unchanged.

The first 'tactile extinction test' indicated that prior to a lesion, the latency to remove the tape was not related to the direction of AMPHinduced rotation. Seven days after a lesion of either the 'dominant' or 'non-dominant' hemisphere, there was a significant increase in the latency to remove the tape from the contralateral paw (paired $t$-test $=2.2, \mathrm{df}=17, P<0.05$ ). At 21 days, however, the animals lesioned in the 'dominant' hemisphere had not improved, but the performance of rats lesioned in the "non-dominant' hemisphere was significantly improved $(F=6.49, \mathrm{df}=1.15, P<0.05)$. The latency to remove tape from the ipsilateral forepaw did not change from prelesion values in either group.

When retested for AMPH-induced rotation, rats lesioned in the 'dominant' hemisphere tended to change their direction of rotation as indicated by a significant increase in rotations ipsilateral to the lesion (prelesion full rotations: 20.9; postlesion full rotations: 142.1 ; paired $t$-test $=3.34$, $\mathrm{df}=9, P<0.01$ ). The direction of the rotational behavior of rats lesioned in the 'non-dominant' hemisphere was unchanged.

Dopamine depletion varied between 48 and $84 \%$, whereas NE depletion did not exceed $33 \%$ in any area. The differences in dopamine levels between the lesioned and non-lesioned sides are shown in Table I. There were no differences in absolute dopamine levels between the dominant and non-dominant structures in either the lesioned or non-lesioned hemisphere. 
The histological analysis indicated that electrodes were all located in the lateral hypothalamus at the level of the ventromedial nucleus, with no differences between the 'dominant' and 'nondominant' lesion groups. Rats continued to gain a significant amount of weight $(F=32.2$, $\mathrm{df}=3,57, P<0.001$ ) during the month following a lesion. The average weight gain during this period was $14 \%$ regardless of lesion group, and did not differ significantly from 3 animals that had no biochemical evidence of a lesion.

The present results implicate forebrain DA systems in eating and drinking elicited by ESLH and they point to clear differences between the two sides of the brain. Damage to the DA systems on the 'dominant' side as defined by the AMPHrotation test is 3 times as likely to disrupt ESLHevoked eating or drinking than a comparable lesion on the 'non-dominant' side. This disruption of eating and drinking evoked by ESLH was not accompanied by a disruption of ad libitum eating and drinking as judged by postlesion body weight. The dissociation of the effects of the lesion on ingestive behavior evoked by hypothalamic stimulation and by hunger and thirst support the suggestion that different mechanisms are involved ${ }^{36}$.

Previous research in this laboratory investigated the effects of unilateral destruction of dopamine pathways on self-stimulation and ESLHevoked behavior obtained from bilateral hypothalamic electrodes (Fray and Valenstein, unpublished). In a number of animals, striking dissociations were observed between the amount of DA depletion and subsequent effects on behavior. Following unilateral lesions of the substantia nigra, self-stimulation and evoked behavior were only minimally reduced in some rats with large DA depletions, while in other animals with smaller DA depletions these behaviors were greatly attenuated. The present results indicate that the variability in the effectiveness of unilateral lesions that was previously observed, can probably be explained by the intrinsic asymmetry of DA systems. These results are also consistent with earlier reports that unilateral lesions of the 'dominant' or 'non-dominant' hemisphere have different effects on rotational behavior and sensorimotor responsiveness ${ }^{25.27}$.
This research was partially supported by NIH Grant MH37277 to T.E. Robinson.

\section{REFERENCES}

I Antelman, S.E., Rowland, N.E. and Fisher, A.E., Stimulation-bound ingestive behavior: a view from the tail, Physiol. Behav., 17 (1976) 743-748.

2 Antelman, S.M. and Szechtman, H., Tail-pinch induces eating in sated rats which appears to depend on nigrostriatal dopamine, Science, 189 (1975) 731-733.

3 Antelman, S.M., Szechtman, H., Chin, P. and Fisher, A.E., Tail-pinch induced eating, gnawing and licking behavior in rats: dependence on the nigrostriatal dopamine system, Brain Research 99 (1975) 319-337.

4 Bachus, S.E. and Valenstein, E.S., Individual behavioral responses to hypothalamic stimulation persist despite destruction of tissue surrounding the electrode tip, Physiol. Behav., 23 (1979) 421-426.

5 Coons, E.E., Levak, M. and Miller, N.E., Lateral hypothalamus: learning of food seeking responses by electrical stimulation, Science, 150 (1965) 1320-1321.

6 Devor, M.G, Wise, R.A., Milgram, N.W. and Hoebel, B.G., Physiological control of hypothalamically elicited feeding and drinking, J. comp. Physiol. Psychol., 73 (1970) 226-233

7 Falk, J.L., The nature and determinants of adjunctive behavior, Physiol. Behav., 6 (1971) 577-588.

8 Felice, L.J., Felice, J.D. and Kissinger, P.T., Determination of catecholamines in rat brain parts by reverse-phase ion-pair liquid chromatography, J. Neurochem., 31 (1978) 1461-1465

9 Glick, S.D., Jerussi, T.P. and Fleisher, L.N., Turning in circles: the neuropharmacology of rotation, Life. Sci., 18 (1976) 889-896.

10 Glick, S.D., Jerussi, T.P., Waters, D.H. and Green, J.P., Amphetamine-induced changes in striatal dopamine and acetylcholine levels and relation to rotation (circling behavior) in rats, Biochem. Pharmacol., 23 (1974) 3223-3225.

11 Glick, S.D., Jerussi, T.P. and Zimmerberg, B., Behavioral and neuropharmacological correlates of nigrostriatal asymmetry in rats. In S. Harnad et al. (Eds.), Lateralization in the Nervous System, Academic Press, New York, 1977, pp. 213-249.

12 Glick, S.D., Meibach, R.C., Cox, R.D. and Maayani, S. Multiple and interrelated functional asymmetries in rat brain, Life Sci., 25 (1979) 395-400.

13 Heilman, K.M., Neglect and related disorders. In K.M. Heilman and E. Valenstein (Eds.), Clinical Neuropsychology, Oxford Press, New York, 1979, pp. 268-307.

14 Jerussi, T.P. and Glick, S.D., Amphetamine-induced rotation in rats without lesions, Neuropharmacology, 13 (1974) 283-286.

15 Jerussi, T.P. and Glick, S.D., Drug-induced rotation in rats without lesions: behavioral and neurochemical indi- 
ces of a normal asymmetry in nigrostriatal function, Psychopharmacology, 47 (1976) 249-260.

$16 \mathrm{Koob}$, G.F., Fray, P.J. and Iversen, S.D., Tail-pinch stimulation: sufficient motivation for learning, Science, 194 (1976) 637-639

17 Mittleman, G. and Valenstein, E.S., Strain differences in eating and drinking evoked by electrical stimulation of the lateral hypothalamus, Physiol. Behav., 26 (1981) 371-378

18 Mittleman, G. and Valenstein, E.S., Ingestive behavior evoked by hypothalamic stimulation and schedule-induced polydipsia are related, Science, 224 (1984) 415-417.

19 Phillips, A.G. and Fibiger, H.C., Deficits in stimulation induced feeding after intraventricular administration of 6-hydroxydopamine in rats, Behav. Biol., 9 (1973) 749-754.

20 Phillips, A.G. and Fibiger, H.C., Long-term deficits in stimulation-induced behaviors and self-stimulation after 6-hydroxydopamine administration in rats, Behav. Biol., 16 (1976) 127-143

21 Phillips, A.G. and Fibiger, H.C., The multivariate nature of motivated behavior elicited by electrical stimulation of the lateral hypothalamus. In W.L. Veale and K. Ledaris (Eds.), Current Studies of Hypothalamic Function, Vol. 2, Karger, Basel, 1978, pp. 195-205.

22 Phillips, A.G. and Nikaido, R.S., Disruption of brain stimulation-induced feeding by dopamine receptor blockade, Nature (Lond.) 258 (1975) 750-751.

23 Robbins, T.W. and Fray, P.J., Stress-induced eating: fact, fiction or misunderstanding? Appetite, 1 (1980) 103-133.

24 Robbins, T.W. and Koob, G.F., Selective disruption of displacement behaviour by lesions of the mesolimbic dopamine system, Nature (Lond.), (1980) 285 409-412.

25 Robinson, T.E., Becker, J.B., Camp, D.M. and Mansour, A., Variation in the pattern of behavioral and brain asymmetries due to sex differences, In S.D. Glick (Ed.), Cerebral Lateralization in Sub-Human Species, Academic Press, New York, in press.

26 Robinson, T.E., Becker, J.B. and Ramirez, V.D., Sex differences in amphetamine-elicited rotational behavior and the lateralization of striatal dopamine in rats, Brain Res. Bull., 5 (1980) 539-545.

27 Robinson, T.E. and Becker, J.B., The rotational behavior model: asymmetry in the effects of unilateral 6-OHDA lesions of the substantia nigra in rats, Brain Res., 264 (1983) 127-131.

28 Rowland, N.E. and Antelman, S.M., Tail pinch induced eating parallels ingestion elicited by electrical brain stimulation, Fed. Proc., 34 (1975) 373.

29 Rowland, N., Marques, D.M. and Fisher, A.E., Compari- son of the effects of brain dopamine-depleting lesions upon oral behaviors elicited by tail pinch and electrical brain stimulation, Physiol. Behav., 24 (1980) 273-281.

30 Schallert, T., Reactivity to food odors during hypothalamic stimulation in rats not experienced with stimulation-induced eating, Physiol. Behav., 18 (1977) 1061-1066.

31 Schallert, T., Upchurch, M., Lobaugh, N., Farrar, S.B., Spirduso, W.W., Gilliam, P., Vaughn, D. and Wilcox, R.E., Tactile extinction: distinguishing between sensorimotor and motor asymmetries in rats with unilateral nigrostriatal damage, Pharm. Biochem. Behav., 16 (1982) $455-462$.

32 Schwartz, A.S., Marchok, P.L. and Flynn, R.E., A sensitive test for tactile extinction: results in patients with parietal and frontal lobe disease, J. Neurol. Neurosurg. Psychiat., 40 (1977) 228-232.

33 Valenstein, E.S., Behavior elicited by hypothalamic stimulation: a prepotency hypothesis, Brain. Behav. Evolut., 2 (1969) 295-316.

34 Valenstein, E.S. Brain stimulation and behavior control. In J.K. Cole and T.B. Sonderegger (Eds.), Nebraska Symposium on Motivation, Univ. of Nebraska Press, Lincoln, 1975, pp. 251-292.

35 Valenstein, E.S., The interpretation of behavior evoked by electrical stimulation. In A. Wauquier and E.T. Rolls (Eds.), Brain-Stimulation Reward. North-Holland, Amsterdam, 1976, pp. 557-575.

36 Valenstein, E.S., Brain mechanisms of reinforcement. In W.H. Sweet, S. Obrador and J.G. Martin-Rodriguez (Eds.), Neurosurgical Treatment in Psychiatry, Pain, and Epilepsy, University Park Press, Baltimore, 1977, pp. 27-49.

37 Valenstein, E.S., Cox, V.C. and Kakolewski, J.W., Modification of motivated behavior elicited by electrical stimulation of the hypothalamus, Science, 159 (1968) 1119-1121.

38 Valenstein, E.S., Cox, V.C. and Kakolewski, J.W., A reexamination of the role of the hypothalamus in motivation, Psychol. Rev., 77 (1970) 16-31.

39 Valenstein, E.S., Lieblich, I., Divar, R., Cohen, E. and Bachus, S.E., Relation between eating evoked by lateral hypothalamic stimulation and tail pinch in different rat strains, Behav. Neur. Biol., 34 (1982) 271-282.

40 Wallace, M., Singer, G., Finlay, J. and Gibson, S., The effect of 6-OHDA lesions of the nucleus accumbens septum on schedule-induced drinking, wheelrunning and corticosterone levels in the rat, Pharmacol. Biochem. Behav., 18 (1983) 129-136.

41 Wise, R.A., Individual differences in the effects of hypothalamic stimulation: The role of stimulation locus, Physiol. Behav., 6 (1971) 569-572. 